\title{
SubJETIVIDADE CONTEMPORÂNEA: NARCISISMO E ESTADOS AFETIVOS EM UM GRUPO DE ADULTOS JOVENS
}

\author{
CONTEMPORARY SUBJECTIVITY: NARCISSISM AND \\ EMOTIONAL STATES IN A GROUP OF YOUNG ADULTS \\ SUBJETIVIDAD CONTEMPORÁNEA: NARCISISMO Y ESTADOS \\ AFECTIVOS EN UN GRUPO DE JÓVENES ADULTOS
}

Flávia Nedeff Langaro*

Silvia Pereira da Cruz Benetti**

\section{RESUMo}

As transformaçóes na sociedade contemporânea evidenciam a ausência de limites e a abundância de paradoxos que passaram a influenciar tanto o social quanto o psiquismo humano, gerando novas formas de subjetivação. Com isso, surgem as patologias do vazio, associadas ao narcisismo e depressão. Este estudo teve como objetivo investigar características de narcisismo, depressão, ansiedade, desesperança e autoestima em 350 jovens adultos universitários. Para tanto, utilizou o Inventário de Ansiedade de Beck (BAI), a Escala de Desesperança de Beck (BHS), o Inventário de Depressão de Beck-II (BDI-II), a Escala de Rosenberg e o Inventário de Personalidade Narcisista (NPI). A análise dos dados foi realizada através de estatística descritiva e inferencial, seguidas do teste t de Student, correlaçóes e Anova para identificar diferenças de médias entre grupos. Como resultado, obteve-se correlação positiva entre narcisismo e autoestima, entre ansiedade e depressão e entre depressáo e desesperança. E encontrou-se uma correlação negativa entre ansiedade e desesperança e entre depressão e autoestima. Esses resultados fornecem elementos importantes tanto no nível acadêmico como no da prática clínica.

Palavras-chave: narcisismo; autoestima; depressão; ansiedade; desesperança.

* Universidade de Passo Fundo, Passo Fundo, RS, Brasil.

** Universidade do Vale do Rio dos Sinos, São Leopoldo, RS, Brasil. 


\section{Abstract}

Transformations in contemporary society through the absence of boundaries and abundance of paradoxes influence both the social and the human psyche, creating new forms of subjectivity. With that, pathologies associated with emptiness, narcissism and depression arise. This study aimed to investigate characteristics of narcissism, depression, anxiety, hopelessness and self-esteem in 350 young adults from a university. For that, it has been used Beck Anxiety Inventory (BAI), Beck Hopelessness Scale (BHS), Beck Depression Inventory-II (BDI-II), the Rosenberg Scale and the Narcissistic Personality Inventory (NPI). Data analysis was performed using descriptive and inferential statistics, followed by the Student $t$ test, correlation and ANOVA to identify the differences in means between groups. As a result, it's obtained a positive correlation between narcissism and self-esteem, between anxiety and depression and between depression and hopelessness. And it's found a negative correlation between anxiety and depression and hopelessness and self-esteem. These results provide important both in academic and clinical practice.

Keywords: narcissism; self-esteem; depression; anxiety; hopelessness.

\section{Resumen}

Las transformaciones de la sociedad contemporánea en la ausencia de límites y la abundancia de las paradojas influyen tanto en lo social y la psique humana, creando nuevas formas de subjetividad. Con eso, vienen los estados de vacíos, patologías asociadas con el narcisismo y la depresión. Este estudio tuvo como objetivo investigar las características del narcisismo, la depresión, la ansiedad, la desesperanza y la auto-estima en 350 adultos jóvenes universitarios. Para ello, fueran utilizados el Inventario de Ansiedad de Beck (BAI), la Escala de Desesperanza de Beck (BHS), el Inventario de Depresión de Beck-II (BDI-II), la Escala de Rosenberg y el Inventario de Personalidad Narcisista (NPI). El análisis de datos se realizó mediante estadística descriptiva e inferencial, seguido por la prueba de la t de Student, ANOVA y correlaciones para identificar las diferencias de medias entre los grupos. Como resultado, se encontró correlación positiva entre el narcisismo y la autoestima, entre la ansiedad y la depresión y entre la depresión y la desesperanza. Y, se encontró una correlación negativa entre la ansiedad y la depresión, y entre la desesperanza y la autoestima. Los resultados aportan elementos importantes tanto en la práctica académica y clínica.

Palabras clave: narcisismo; depresión; ansiedade; autoestima; desesperanza. 


\section{Introdução}

A sociedade contemporânea vem sofrendo uma série de transformaçóes em decorrência dos avanços na industrialização, do processo de globalização, das constantes mudanças na tecnologia e da maior dependência da informática e da realidade virtual, dentre outros (Brum, 2004). Com relação a essas mudanças, já na década de 1980 Lipovetsky (1989) apontava que, em nível social, ocorria uma proliferação de imagens, ideologias terapêuticas, culto ao consumo, transformaçôes da família, educação permissiva e relações humanas cada vez mais bárbaras e conflitivas. Surgia, então, uma sociedade marcada por muitas fragmentaçóes, ausência de limites e abundância de paradoxos que passaram a influenciar tanto o social quanto o psiquismo humano.

Como consequência, nos ideais contemporâneos, conforme Faveret, Mendonça, Coelho e Faustini (2007), predominam a desvalorização do passado e a procura do prazer intenso, impulsivo e momentâneo, em busca de gratificaçóes imediatas. Do mesmo modo, cresce a banalização das relaçóes pessoais, tornando os relacionamentos amorosos e afetivos superficiais e passageiros, com pouca condição de se transformarem em vínculos mais duradouros. Os afetos tornam-se tênues e as relaçóes são vividas em meio ao tédio, à futilidade e ao vazio. Nesse sentido, a apatia seletiva, o descompromisso emocional frente aos outros, a renúncia ao passado e ao futuro, a determinação de viver um dia de cada vez, o gosto pelo efêmero e pelo descartável em condiçôes extremas passaram a configurar a vida das pessoas em condiçôes normais da sociedade contemporânea, as quais vivem em busca da satisfação imediata dos desejos (Berlinck, 2008; Lasch, 1983). Assim, surge uma sociedade que tende à desindividuação, à constituiçâo de egos frágeis, extremamente dependentes do investimento do outro, condição até mesmo de suas existências (Amaral, 2000; Lasch, 1983), prevalecendo a noção de sujeito como individual, solitário e indiviso. A atençáo se fixa na homogeneidade, o sujeito é único, mas igual a todos (Ferrari, 2006).

Esses momentos de indefinição, de mudança em relação a valores e papéis sociais carregam componentes de angústia, a qual se traduz em novas formas de adoecimento psíquico e de subjetivação (Brum, 2004). Assim, diagnósticos frequentes de depressão, drogadição, anorexia, bulimia, violência, consumismo, doenças psicossomáticas, síndrome do pânico têm sido associados ao quadro das novas patologias, as quais evidenciam dimensôes desagregadoras da cultura contemporânea (Favaret et al., 2007).

Verifica-se, então, o lugar da cultura como elemento coadjuvante na constituição do psiquismo humano, já que a subjetividade é construída a partir de 
articulações das relaçóes culturais da época com a história individual. Nesse sentido, cada época histórica tem uma forma própria de sentir, trabalhar, desejar e viver (Berlinck, 2008; Sennett, 1975; Tajfel, 1984; Giddens, 2002; Hall, 2002). Nesse aspecto, a sociedade atual pode ser comparada com a fase do narcisismo no desenvolvimento libidinal do indivíduo. No narcisismo, o ego se comporta como objeto de seu próprio amor, idealizando e superestimando a si mesmo, experimentando prazer por se sentir especial e perfeito. Assim, o que caracteriza a sociedade é a procura da vida feliz, a qual é abreviada à ideia de bem-estar e à de satisfação prazerosa, obtidas ilusoriamente pela identificação, através do consumismo, da valorização da beleza, da busca pelo sucesso (Brum, 2004; Lasch, 1983).

Como consequência desse processo, questionam-se as relaçóes entre os ideais contemporâneos narcisistas e o desenvolvimento psíquico do indivíduo adulto que, ao contrário, pressupóe uma singularização baseada na aceitação de limites e faltas impostos pela aquisição de uma identidade pessoal. Esta, por sua vez, dissipa a onipotência narcísica, dando ao sujeito uma noção de si mesmo, com seus ideais e valores (Ideal do Ego), minimizando a sensação de desamparo, falta e vazio (Savietto \& Cardoso, 2006). Porém, considerando-se a ênfase na gratificação narcísica contemporânea, o que podemos dizer acerca das manifestaçóes patológicas contemporâneas ligadas à cultura do vazio?

A crise mais ampla da modernidade incide na construção da subjetividade contemporânea, ou seja, na própria constituição do sujeito psíquico. $\mathrm{O}$ vazio e o desamparo sentido pelo sujeito geram um sofrimento que pertence ao indivíduo isoladamente, mas também e concomitantemente à sociedade e à cultura na qual o indivíduo está inserido (Monti, 2008). Dois aspectos se destacam nesse sentido, a menção do gradual aumento de características narcisistas de personalidade (Twenge, Konrath, Foster, Campbell, \& Bushman, 2008; Twenge, 2013) e também de estados afetivos depressivos (Kelly, 2006) identificados em estudos internacionais ao longo das últimas décadas.

No desenvolvimento saudável do sujeito, a separação dos pais e o desenvolvimento de um eu individualizado procede durante o final da adolescência e o aparecimento da vida adulta. Isso é facilitado pela presença do narcisismo adaptável, o qual apoia e liberta o quase adulto para desenvolver seus/suas próprias metas, valores e esforço automotivado. Sob circunstâncias ideais, o desenvolvimento adulto é apoiado por este narcisismo saudável; o indivíduo torna-se bem-sucedido e realizado e, a partir dessas realizaçóes na realidade, ele ou ela desenvolve um narcisismo saudável futuro. Em suma, o fracasso para individualizar-se, para desenvolver um eu autônomo, resulta no desenvolvimento do narcisismo 
mal-adaptável. Tal narcisismo funciona para proteger o indivíduo de experiências de desapontamento e desilusão associadas ao fracasso para alcançar metas não realistas, grandiosas (Westen, 1990) e do reconhecimento do eu "falso" e pobremente articulado eu (Miller, 1981). No entanto, a inaptidão para a separação e para se tornar autônomo, e o narcisismo mal-adaptável resultante, impedem o crescimento psíquico e por último, a saúde psíquica.

Assim, o narcisismo pode ser descrito por dois polos: o narcisismo patológico e o narcisismo normal (Pincus, Ansell, Pimentel, Cain, Wright, \& Levy, 2009). Essa noção sustenta-se em aspectos da personalidade voltados para autoestima e conhecimento, tais como preservação de interesses pessoais, investimento em crescimento e maturação, que seriam os aspectos positivos do narcisismo. $\mathrm{O}$ narcisismo saudável caracteriza-se por uma boa autoestima, a qual apoia o esforço para conquistas e carreiras de sucesso (Cramer $\&$ Jones, 2008), bem como para a iniciativa humana, criatividade e bondade (Kubarych, Deary, \& Austin, 2004).

Em oposição, os aspectos negativos referem-se a sentimentos de grandiosidade e autossuficiência, à falta de empatia, agressividade, impulsividade e oscilações depressivas intensas quando frente à frustração. O narcisismo mal-adaptável, que ocorre quando o eu está disperso ou inseguro, caracteriza-se pela autoampliação, procura de poder e condescendência como forma de proteçâao contra sentimentos de inadequação. Nesse sentido, evidências clínicas indicam que esses indivíduos frequentemente têm um senso abaixo da baixa autovalorização. Portanto, o narcisismo mal-adaptável é provável na influência do impacto negativo na saúde psíquica, provocando o desajustamento do sujeito. Por isso, ainda que sob distintos vértices compreensivos sobre o narcisismo e sua origem, tanto a psicologia, a psiquiatria e a psicanálise abordam elementos comuns relativos à capacidade de manutenção de uma imagem positiva de si mesmo. Entretanto, consideram que, em alguns aspectos, o narcisismo assumiria uma conotação negativa, pois impediria o sujeito de descentrar-se de si mesmo, isto é, de ter a capacidade de reconhecer seus limites, aceitar frustraçóes e, igualmente, obter satisfação pessoal (Cramer \& Jones, 2008).

Considerando esses aspectos, o presente artigo teve como objetivo identificar as características narcísicas de personalidade em um grupo de jovens adultos universitários, verificando associaçôes entre narcisismo, autoestima, manifestação de sintomas depressivos e de ansiedade e, por fim, o nível de desesperança (ou esperança) nos sujeitos participantes. 


\section{Metodologia}

\section{Delineamento}

Esse estudo assumiu um delineamento quantitativo, do tipo transversal.

\section{Participantes}

Os participantes foram 350 jovens adultos universitários, estudantes de diferentes cursos de graduação, de ambos os sexos (35,4\% homens, $64,6 \%$ mulheres), com idade entre 18 e trinta anos, residentes em uma cidade do interior da regiáo noroeste do estado do Rio Grande do Sul, a qual possui uma população estimada em 186.028 habitantes, sendo considerada um polo universitário devido a abranger cinco instituiçóes de ensino superior.

A seleção dos participantes ocorreu de forma aleatória. Os alunos eram provenientes dos semestres iniciais dos cursos de Psicologia, Engenharia Civil, Direito, Odontologia, Farmácia e Administração de uma universidade. Esses cursos foram organizados em quatro áreas de conhecimento: Ciências Humanas, Ciências Sociais, Ciências Exatas e Ciências da Saúde.

\section{Coleta de dados}

A coleta de dados ocorreu na sala de aula dos diferentes cursos de graduação de uma universidade. Após permissão da coordenação e do professor, o qual ministrava a disciplina no momento, a pesquisadora e uma aluna do curso de Psicologia entraram na sala, apresentaram-se aos alunos, realizando o primeiro contato com os participantes, no qual ocorreu o rapport, com objetivo de esclarecer o processo da pesquisa. Em caso de aceitação, foi assinado pelos acadêmicos o Termo de Consentimento Livre Esclarecido, no qual foi explicada a natureza e relevância do trabalho a ser desenvolvido e garantido o sigilo quanto à identificação pessoal dos participantes. Este termo foi impresso em duas vias, permanecendo uma cópia com a pesquisadora e outra com os sujeitos da pesquisa. Após, deu-se inicio a coleta dos dados sociodemográficos e administração dos instrumentos: Inventário de Ansiedade Beck (BAI), Inventário de Desesperança Beck (BHS), Inventário de Depressão Beck (BDI-II), Escala de Autoestima de Rosenberg e Inventário de Personalidade Narcisista (NPI), respectivamente. Esse processo durou aproximadamente 1 hora. 


\section{Instrumentos}

Ficha de dados sociodemográficos

Visando identificar as principais características pessoais e familiares dos jovens adultos, foi aplicado um questionário de dados sociodemográficos aos estudantes universitários. O questionário inclui questôes sobre idade, naturalidade, grau de escolaridade, composição familiar, estado civil, emprego atual e profissão.

\section{Inventário de Ansiedade de Beck (BAI)}

O BAI foi criado por Beck, Steer e Garbin (1988) como uma escala autoaplicativa para medir a intensidade de sintomas ansiosos. O BAI também foi originalmente desenvolvido para medir sintomas em uma população previamente diagnosticada como portadora de transtorno de ansiedade. Após algum tempo de uso, observou-se que era um instrumento adequado para avaliação da população em geral. No Brasil, foi validado por Cunha (2001). É composto por 21 itens, que devem ser avaliados pelo próprio indivíduo numa escala de quatro pontos: 1- "absolutamente não"; 2- "levemente"; 3- "moderadamente"; 4-"gravemente". O tempo de aplicaçáo é de cerca de cinco a dez minutos. Os escores de sintomas ansiosos para o BAI são os seguintes: 0-10: sintomas mínimos; 11-19: sintomas leves; 20-30: sintomas moderados; 31-63: sintomas graves.

Ressalva-se que a estimativa de fidedignidade, baseada no Coeficiente Alfa de Cronbach do BAI neste estudo, foi de 0.88 , o que pode ser interpretado como satisfatório, demonstrando que o instrumento possui um bom nível de precisão para medir intensidade de depressão.

\section{Escala de Desesperança de Beck (BHS)}

O BHS é uma escala dicotômica que mede a dimensão do pessimismo ou da extensão das atitudes negativas frente ao futuro (Beck \& Steer, 1993). Engloba vinte itens, consistindo em afirmações que o sujeito deve examinar e classificar, cada uma como certo ou errada, para descrever sua atitude na direção da desesperança na última semana, incluindo hoje. O seu escore total é resultado da soma dos itens individuais (Beck \& Steer, 1993). Na sua versão em português (Cunha, 2001), a BHS foi testada em amostras clínicas e na população geral, demonstran- 
do dados satisfatórios de fidedignidade e validade. A BHS, neste estudo, obteve coeficiente de consistência interna de 0.81 .

Inventário de Depressão de Beck-II (BDI-II)

O BDI-II em língua inglesa foi submetido à tradução para o português por dois pesquisadores bilíngues da Universidade de São Paulo e foi retrotraduzida por um professor de inglês nativo. A versão original foi comparada com a versão traduzida e retrotraduzida por um grupo de especialistas da área de psicologia e psiquiatria. Esta versão preliminar foi comparada novamente com a versão em português produzida pela equipe da Pontifícia Universidade Católica do Rio Grande do Sul. A versão final foi obtida após nova reunião entre os especialistas da Universidade de São Paulo e PUC-RS (Gorenstein, Pang, Argimon, \& Werlang, 2011) juntamente com a equipe da Casa do Psicólogo. O BDI-II final foi testado em vinte estudantes universitários, com o objetivo de verificar a compreensibilidade do instrumento e eventuais imprecisóes. $\mathrm{O}$ instrumento possui 21 itens. Para cada um deles há quatro (com escore variando de 0 a 3 ) afirmativas de resposta (com exceção dos itens 16 e 18, em que existem sete afirmativas, sem, contudo variar o escore), entre as quais o sujeito escolhe a mais aplicável a si mesmo para descrever como esteve se sentindo nas duas últimas semanas, incluindo o dia de hoje (Beck, Ward, Mendelson, Mock, \& Erbaugh, 1996). Estes itens dizem respeito a níveis de gravidade crescentes de depressáo, e o escore total é resultado da soma dos itens individuais, podendo alcançar o máximo de 63 pontos. A pontuação final é classificada em níveis mínimo, leve, moderado e grave, indicando assim a intensidade da depressão. Nesse estudo, o instrumento obteve Alpha Crombach de 0.81 .

Inventário de Personalidade Narcisista (NPI)

O NPI (Corry, Merritt, Mrug, \& Pamp, 2008) é um questionário de autorrelato desenvolvido para avaliar o narcisismo como uma característica de personalidade. Cada item é composto de um par de declaraçôes narcisistas e não narcisistas. Apesar de várias versóes do NPI estarem disponíveis, os quarenta itens NPI (Raskin \& Terry, 1988) foram utilizados correlacionados com a versão original de 54 itens e é a versão mais amplamente utilizada em pesquisas hoje (Raskin \& Terry, 1988). Raskin e Terry (1988), mediante análise fatorial do instrumen- 
to, encontraram sete fatores componentes do escore total de narcisismo. Estes componentes são os escores parciais correspondentes às sete subescalas do instrumento, denominados de dimensóes narcísicas, a saber: autoridade, exibicionismo, superioridade, intitulação, exploratividade, autossuficiência e vaidade (Magalhães \& Koller, 1994). Neste estudo, o coeficiente de consistência interna foi de 0.79.

\section{Escala de Rosenberg}

A escala de Rosenberg foi desenvolvida em 1979 e é uma medida unidimensional constituída por dez afirmaçóes relacionadas a um conjunto de sentimentos de autoestima e autoaceitação que avalia a autoestima global. Os itens são respondidos em uma escala tipo Likert de quatro pontos variando entre concordo totalmente, concordo, discordo e discordo totalmente. Neste estudo, foi utilizada a versão adaptada para o português por Hutz (2000), cujos resultados iniciais já indicavam a unidimensionalidade do instrumento e características psicométricas equivalentes às encontradas por Rosenberg (1989). Neste estudo, o coeficiente de consistência interna foi de 0.73 .

\section{Análise dos dados}

Após a aprovação do projeto deste estudo pelo Comitê de Ética em Pesquisa da Unisinos, respeitando todas as normas da resolução 196/96 do Ministério da Saúde, foi realizado contato com a instituição de ensino superior para obter a autorização para a coleta de dados da pesquisa. Em seguida, realizou-se o contato com os estudantes e o convite de participação no estudo.

A administração dos instrumentos foi realizada, após o aceite do estudante em participar da pesquisa, na própria instituição de ensino superior, de forma coletiva, durante o horário acadêmico. Os instrumentos foram interpretados de acordo com as instruçóes referentes a cada um. Todas as informaçóes coletadas foram organizadas em banco de dados no programa estatístico Statistical Package for the Social Sciences SPSS, versão 17.0, para então serem analisadas. Para o estudo de fidedignidade na avaliação da consistência interna, foi utilizado o teste de Alfa de Cronbach. A análise dos dados foi realizada através de estatística descritiva e inferencial, seguidas do teste t de Student, correlaçóes e Anova para identificar diferenças de médias entre grupos. 


\section{Procedimentos éticos}

Este estudo foi encaminhado para o Comitê de Ética em Pesquisa da Unisinos, respeitando todas as normas da resoluçấo 196/96 do Ministério da Saúde. Portanto, somente foi iniciado o estudo após a autorização do Comitê de Ética e a concordância dos sujeitos. Também foi solicitada a autorização da coordenação dos cursos escolhidos da universidade. Alunos identificados como necessitando de acompanhamento psicológico foram encaminhados para a clínica psicológica da universidade.

\section{Resultados}

A média total no NPI foi de 12.60 ( $\mathrm{DP}=5.74)$, sendo que os escores variaram entre um a trinta pontos. Já a média na Escala de Rosenberg foi de 21.62 $(\mathrm{DP}=7.06)$, variando entre seis a quarenta pontos. Em relação às escalas Beck, os resultados encontraram foram: média de $2.68(\mathrm{DP}=2.43)$ na escala de Desesperança de Beck, variando entre 0 e 16 pontos; média de $8.16(\mathrm{DP}=6.55)$ no $\mathrm{BDI}$, variando entre o e 44 pontos e média de $9.58(\mathrm{DP}=8.46)$ no $\mathrm{BAI}$, que variou entre 0 e 49 pontos. $\mathrm{O}$ teste $\mathrm{T}$ de Student foi utilizado para comparar as médias de homens e mulheres em relação aos escores totais do NPI total e também em relaçâo aos demais instrumentos (Tabela 1 ).

Verificaram-se diferenças significativas entre as médias de homens e mulheres em relação ao escore total do NPI, do Inventário de Ansiedade de Beck, Rosenberg e também no Inventário de Depressão de Beck. Correlaçôes de Pearson também foram calculadas entre os instrumentos utilizados neste estudo. Os resultados encontram-se agrupados na tabela 2.

Conforme expressa a tabela 2 , houve correlação positiva e fraca entre o escore total do NPI com a Escala de Rosenberg ( $r=0.30, p=0.001)$, o que sugere que, na medida em que aumenta a pontuação no inventário NPI, aumenta a pontuação na escala de autoestima. Do mesmo modo, houve correlação positiva e moderada entre o Inventário de Ansiedade de Beck com o Inventário de Depressão de Beck ( $r=0.60, p=0.001)$, o que mostra que, na medida em que os participantes apresentaram mais ansiedade, também se verificou maior frequência de sintomas de depressão. O Inventário de Ansiedade de Beck também apresentou correlação negativa e moderada com o Inventário de Desesperança de Beck $(\mathrm{r}=-0.37, \mathrm{p}=0.001)$, mostrando que, na medida em que aumentam os sintomas de ansiedade, diminuem os sintomas de desesperança. 
Tabela 1. Médias, Desvios-Padrão e os Valores do Teste T em relação aos instrumentos utilizados de acordo com o sexo dos respondentes.

\begin{tabular}{lcccccc}
\hline & Sexo & N & Média & Desvio-Padráo & Valor do T & Significância \\
\hline Rosenberg & M & 123 & 20.30 & 6.24 & -2.58 & $0.01^{*}$ \\
& F & 226 & 22.34 & 7.38 & & \\
BHS & M & 121 & 2.51 & 1.87 & -0.93 & 0.35 \\
& F & 226 & 2.76 & 2.68 & & \\
BDI & M & 117 & 6.88 & 6.04 & -2.65 & $0.008^{*}$ \\
& F & 219 & 8.85 & 6.72 & & \\
BAI & M & 121 & 7.27 & 6.88 & -3.80 & $0.00^{*}$ \\
& F & 223 & 10.83 & 8.97 & & \\
& & & & & & \\
NPI & M & 115 & 14.24 & 6.18 & 3.85 & \\
\hline
\end{tabular}

Nota. ${ }^{*}$ indica que os valores diferem estatisticamente.

Tabela 2. Correlaçóes de Pearson entre os Escores Totais do NPI, BAI, BDI, BHS e Escala de Rosenberg

\begin{tabular}{lcrrrc}
\hline & $\mathbf{1}$ & $\mathbf{2}$ & $\mathbf{3}$ & $\mathbf{4}$ & $\mathbf{5}$ \\
\hline 1. NPI & 1 & -.04 & -.02 & -.04 & $.30^{* *}$ \\
2. BAI & & 1 & $.60^{* *}$ & $-.51^{* *}$ & $-.37^{* *}$ \\
3. BDI & & & 1 & $.54^{* *}$ & $-.48^{* *}$ \\
4. BHS & & & 1 & $.51^{* *}$ \\
5. Rosenberg & & & & 1 \\
\hline Nota. ${ }^{*} \mathrm{p}<0,05^{* *} \mathrm{p}=0,001$ (2-tailed) & & & & &
\end{tabular}

O Inventário de Desesperança de Beck apresentou correlação positiva e moderada com o inventário de Depressão de Beck ( $\mathrm{r}=0.54, \mathrm{p}=0.001)$, mostrando que, quanto mais sintomas de depressão a pessoa apresenta, mais sintomas de 
desesperança também foram verificados. Por fim, a escala de Rosenberg apresentou uma correlação negativa e moderada com o Inventário de Depressão de Beck (BHS) $(r=-0.48, p<0.05)$, indicando que uma vez que aumentam os sintomas de depressão, diminui a autoestima dos respondentes.

Para precisar quais dimensôes do NPI haviam se correlacionado com a escala Rosenberg foram calculadas a Correlação de Pearson entre as varáveis escore médio total do NPI e os fatores Autoridade, Exibicionismo, Superioridade, Autovaloração, Exploração, Autossuficiência e Autointitulação. Os resultados apontaram para correlaçóes positivas e fracas entre Autoestima e Autoridade $(\mathrm{r}=0.33$, $\mathrm{p}<0.00)$, Superioridade $(\mathrm{r}=0.26, \mathrm{p}<0.00)$, Autovaloração $(\mathrm{r}=0.30, \mathrm{p}<0.00)$, e Autossuficiência $(\mathrm{r}=0.24, \mathrm{p}<0.03)$.

Para investigar as possíveis diferenças entre as médias dos instrumentos em relação às faixas etárias e em relação aos cursos, conduzimos uma One-Way Anova, cujos resultados não apresentaram efeitos significativos em relação às faixas etárias. Por outro lado, em relação aos cursos, verificaram-se efeitos significativos (Tabela 3).

De acordo com a tabela 3, constata-se que houve interação significativa entre os estudantes dos cursos das áreas de Exatas, Ciências Humanas e Saúde no que diz respeito ao NPI $(\mathrm{F}=9.56, \mathrm{p}<0.001)$ e à Escala de Rosenberg $(\mathrm{F}=32.25$, $\mathrm{p}<0.001)$. Utilizou-se o pós-teste de Tukey para checar a natureza de tais diferenças, que mostrou que, no tocante ao NPI, os estudantes dos cursos de Exatas apresentaram médias superiores $(\mathrm{M}=14.62, \mathrm{DP}=6.05)$ às apresentadas pelos estudantes de Ciências Humanas $(\mathrm{M}=11.42$, $\mathrm{DP}=5.45)$ e Saúde $(\mathrm{M}=12.00, \mathrm{DP}=5.37)$. Do mesmo modo, em relação à escala de Rosenberg, os estudantes dos cursos de Ciências Humanas apresentaram médias superiores $(\mathrm{M}=25.56, \mathrm{DP}=7.65)$ às apresentadas pelos estudantes de Exatas $(M=19.29, \mathrm{DP}=6.06)$ e Saúde $(\mathrm{M}=19.98$, $\mathrm{DP}=5.62)($ Figura 1). 
Tabela 3. Comparação das médias no NPI, BAI, BDI, BHS

e Escala de Rosenberg em relação aos cursos dos estudantes

\begin{tabular}{|c|c|c|c|c|c|c|c|c|}
\hline & & \multirow{2}{*}{$\mathbf{N}$} & \multirow{2}{*}{ Média } & \multirow{2}{*}{$\begin{array}{l}\text { Desvio- } \\
\text {-Padrão }\end{array}$} & \multicolumn{2}{|c|}{$\begin{array}{l}\text { Intervalo de con- } \\
\text { fiança das médias }\end{array}$} & \multirow{2}{*}{$\mathbf{F}$} & \multirow{2}{*}{$\mathbf{p}$} \\
\hline & & & & & Superior & Inferior & & \\
\hline \multirow[t]{4}{*}{ NPI } & $\begin{array}{l}\text { Ciências } \\
\text { Humanas }\end{array}$ & 112 & 11.42 & 5.45 & 10.40 & 12.44 & \multirow{4}{*}{9.56} & \multirow{4}{*}{$0.00^{* *}$} \\
\hline & Saúde & 118 & 12.00 & 5.37 & 11.02 & 12.98 & & \\
\hline & Exatas & 100 & 14.62 & 6.05 & 13.41 & 15.82 & & \\
\hline & Total & 330 & 12.60 & 5.75 & 11.97 & 13.22 & & \\
\hline \multirow[t]{4}{*}{ BAI } & $\begin{array}{l}\text { Ciências } \\
\text { Humanas }\end{array}$ & 115 & 10.00 & 8.43 & 8.44 & 11.55 & \multirow{4}{*}{0.20} & \multirow{4}{*}{0.81} \\
\hline & Saúde & 120 & 9.49 & 8.62 & 7.93 & 11.05 & & \\
\hline & Exatas & 107 & 9.28 & 8.38 & 7.68 & 10.89 & & \\
\hline & Total & 342 & 9.59 & 8.46 & 8.69 & 10.50 & & \\
\hline \multirow[t]{4}{*}{ BDI } & $\begin{array}{l}\text { Ciências } \\
\text { Humanas }\end{array}$ & 113 & 8.55 & 6.99 & 7.25 & 9.86 & \multirow{4}{*}{0.43} & \multirow{4}{*}{0.64} \\
\hline & Saúde & 117 & 8.11 & 5.69 & 7.06 & 9.15 & & \\
\hline & Exatas & 104 & 7.73 & 6.93 & 6.38 & 9.08 & & \\
\hline & Total & 334 & 8.14 & 6.54 & 7.43 & 8.84 & & \\
\hline \multirow[t]{4}{*}{ BHS } & $\begin{array}{l}\text { Ciências } \\
\text { Humanas }\end{array}$ & 117 & 2.76 & 2.81 & 2.25 & 3.28 & \multirow{4}{*}{0.17} & \multirow{4}{*}{0.84} \\
\hline & Saúde & 120 & 2.58 & 2.23 & 2.17 & 2.98 & & \\
\hline & Exatas & 108 & 2.66 & 2.21 & 2.24 & 3.08 & & \\
\hline & Total & 345 & 2.67 & 2.43 & 2.41 & 2.93 & & \\
\hline \multirow[t]{4}{*}{ Rosenberg } & $\begin{array}{l}\text { Ciências } \\
\text { Humanas } \\
\end{array}$ & 117 & 25.56 & 7.65 & 24.16 & 26.96 & & \\
\hline & Saúde & 121 & 19.98 & 5.62 & 18.97 & 20.99 & \multirow[t]{3}{*}{32.25} & \multirow[t]{3}{*}{$0.00^{* *}$} \\
\hline & Exatas & 109 & 19.29 & 6.06 & 18.14 & 20.44 & & \\
\hline & Total & 347 & 21,64 & 7.07 & 20.90 & 22.39 & & \\
\hline
\end{tabular}

Nota. ${ }^{*} \mathrm{p}<0,05{ }^{* *} \mathrm{p}=0,001$ (2-tailed) 
Figura 1. Localização das médias que apresentaram diferença significativa entre os cursos.

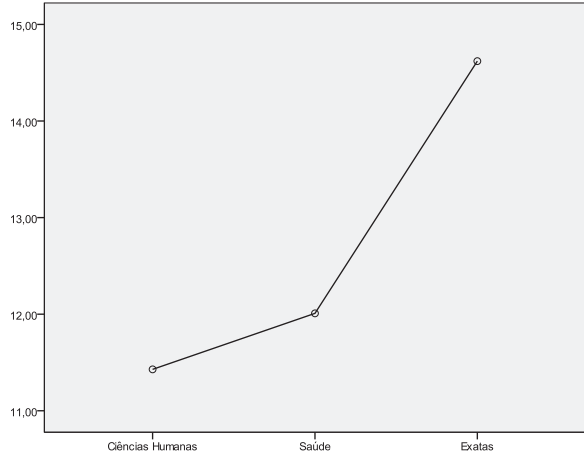

NPI

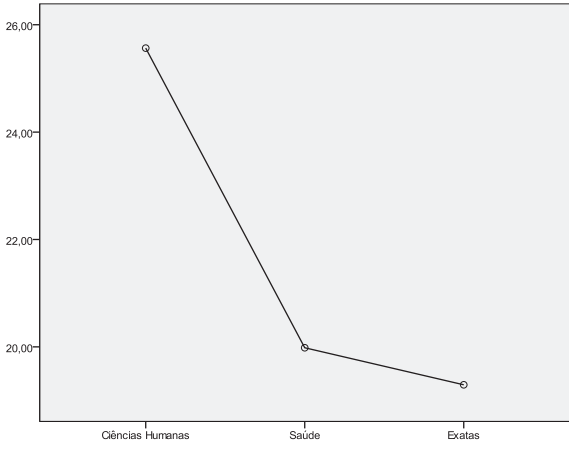

Rosenberg

\section{Discussão}

Estudos internacionais identificaram, ao longo das últimas duas décadas, um aumento significativo nas médias totais do narcisismo, indicando que características narcísicas têm assumido uma maior importância nos aspectos de personalidade de jovens, refletindo tendências de individualismo, autocentramento e necessidade de gratificação pessoal. Por exemplo, entre estudantes americanos a análise de pesquisas da década de 1990 apontou uma média no NPI de 15.88 nas amostras, enquanto que nos estudos de 2006 este valor foi de 17.62 (Twenge et al., 2008).

Levando em conta os valores identificados em estudos, a média geral obtida no NPI no presente estudo foi de 12.60, não tão altos como os mencionados por Twenge et al. (2008). Essa característica poderia levar à suposição de que características associadas ao individualismo, autovaloração e uma perspectiva mais autocentrada não seriam predominantes entre os jovens brasileiros. Desse modo, os valores apresentados pelo grupo de estudantes investigado foram menores, quando comparados com os apontados por estudos internacionais. Cabe ressaltar que a média masculina neste estudo foi significativamente maior e similar aos estudos americanos da década de 1990. Da mesma forma, a questão do menor índice de narcisismo identificado nas mulheres confirmou as questôes de gênero ligadas ao papel mais cuidador, afetivo e empático das mulheres, em contraposição aos aspectos mais competitivos masculinos. Esses resultados podem ter sido 
relacionados às características da amostra, porém indicam a importância de realizar estudos comparativos com outros grupos e faixas etárias distintas.

Especificamente, a análise das características narcisistas por área do curso também apontou aspectos interessantes, tal como a média significativamente maior nos escores do NPI nos cursos de exatas e saúde, seguidos por último pela área das ciências humanas. Em um estudo envolvendo a avaliação de características narcísicas avaliadas pelo instrumento NPI, Hill e Yousey (1998) verificaram que, dentre as profissóes professor universitário, políticos, bibliotecários e clérigos, os maiores valores do NPI eram entre os políticos e os menores entre os clérigos. Vê-se que é possível identificar padrôes entre as distintas profissóes no que diz respeito às características narcisistas dos sujeitos. No presente estudo, estudantes de áreas voltadas para o estudo e compreensão de temas relativos a questóes sociais, emocionais, históricas e políticas do sujeito e de grupos humanos manifestaram um menor escore narcisista, o que reflete as próprias escolhas de identificação profissional associadas a temáticas sustentadas em cooperação, reconhecimento de necessidades humanas e seus conflitos nas distintas dimensóes. Complementando essas características, houve maior autoestima entre os estudantes da área das humanas, traços que, conforme Hutz e Zanon (2011) associam-se ao maior bem-estar, autovaloração e percepção de eficácia.

As demais análises em relação ao Inventário de Ansiedade de Beck e também ao Inventário de Depressão de Beck-II indicaram diferenças significativas entre homens e mulheres. Nesse caso, os resultados confirmaram resultados já identificados em outros estudos sobre maiores escores depressivos em mulheres (Baptista, Baptista, \& Oliveira, 1999; Teng, Humes, \& Demetrio, 2005; Martin, Quirino, \& Mari, 2007).

Finalmente, as correlaçóes entre os escores médios dos instrumentos evidenciou que um maior narcisismo estaria positivamente associado à maior autoestima. Segundo Twenge et al. (2008), essas associaçôes se dariam com as dimensóes mais saudáveis do narcisismo avaliadas pelo NPI, as quais referem-se ao Autoritarismo/Liderança, Autossuficiência/Superioridade. Já as dimensões Exploração e Exibicionismo seriam os aspectos negativos do narcisismo e, ao contrário, não se relacionariam com as características positivas de autoestima. No presente estudo, as correlações identificadas foram ao encontro dos aspectos positivos do narcisismo e autoestima, apontando que os sujeitos com percepção positiva de si mesmos apresentavam características ligadas à dimensão do narcisismo não patológico.

Nessa direção, os autores Twenge et al. (2008) salientam que o narcisismo não-patológico refere-se a uma visão positiva e aumentada do eu, como poder, importância, atração física, por exemplo, e é associado à extroversão social. 
Contudo, ressalva-se que as pessoas com alto narcisismo possuem relativamente menos interesse em formar ligaçóes acaloradas e emocionalmente íntimas com os outros. O narcisista procura agradar o outro, buscando sua atençáo, bem como oportunidade para conquistar o prestígio das pessoas. Ainda, as pessoas com alto nível de narcisismo também agem com agressão, quando são rejeitadas ou insultadas. Muitos desses comportamentos podem ser potencialmente explicados pela ligação do narcisismo com a impulsividade.

Segundo Twenge e Foster (2010), o nível de narcisismo tem mudado com o passar das geraçóes, concomitantemente com o aumento do individualismo na sociedade e o aumento de características individualistas. Outras posições, porém, argumentam (Trzesniewski, Donnellan, \& Robins, 2008, Trzesniewski \& Donnellan, 2010) que o aumento da assertividade e do valor próprio não está associado a aspectos negativos do desenvolvimento dos jovens, os quais apresentam maior empreendedorismo e envolvimento social.

Assim, a pergunta "O aumento do narcisismo é uma coisa ruim?" pode ser respondida, por um lado, ressaltando-se o fato de o narcisismo estar ligado a uma gama de resultados emocionais positivos. Inclui-se, aí, a autoestima, o afeto positivo, a extroversão e a satisfação da vida, assim como a simpatia, o desempenho elevado em tarefas de avaliação pública, vitórias em curto prazo em tarefas competitivas e emergentes e capacidade de liderança (Trzesniewski, Donnellan, \& Robins, 2008). Por outro lado, o narcisismo também apresenta muitos custos para o eu, tais como julgamentos distorcidos das habilidades dos outros, excesso de confiança, transtornos ligados ao comportamento abusivo, incluindo o abuso de álcool, o comprar compulsivamente e entrar em jogos de azar patológicos (Monti, 2008; Savietto \& Cardoso, 2012; Twenge, 2013). Muitos dos custos do narcisismo são enfrentados pelas outras pessoas e não pelo próprio narcisista. Entre os custos, incluem-se: relacionamentos com problemas românticos, agressões, ataques, crimes do "colarinho branco", entre outros.

Em suma, os aspectos negativos do narcisismo estão associados com os benefícios para o próprio indivíduo que são primariamente afetivos e mais evidentes em curto prazo, mas os custos do narcisismo são pagos pelos outros e, ao final, pelo próprio indivíduo. Assim, as implicaçôes do aumento no narcisismo podem ser positivas, mas, se exacerbadas, transformam-se em características negativas para outras pessoas, para a sociedade e para o indivíduo. 


\section{Consideraçóes finais}

Ainda que algumas limitaçóes necessitem ser apontadas neste estudo, no sentido da restriçáo amostral em termos de contexto, os resultados evidenciaram características interessantes quanto aos aspectos narcisistas do grupo e sua relação com a autoestima, a ansiedade, a depressão e a desesperança. Ainda, destaca-se não terem sido identificadas correlaçôes positivas entre narcisismo e sintomas de depressão e ansiedade. Ao contrário, os resultados apontaram associaçóes com os aspectos positivos da personalidade dos participantes, tal como a autoestima.

Finalmente, em termos do instrumento, os resultados encontrados foram similares aos estudos originais, o que não impede que novas análises, utilizando-se de amostras brasileiras, possam contribuir para o aprimoramento do instrumento. Ainda assim, os valores identificados neste estudo indicam que o instrumento tem condições de aplicação para estudo no Brasil em relação à identificação de características narcisistas. Cabe também ressaltar que os dados são limitados aos estudantes universitários. Assim, uma pesquisa futura poderá examinar mudanças no narcisismo entre outras populaçóes - por exemplo, adultos e adolescentes.

\section{Referências}

Amaral, M. (2000). O mal-estar na psicanálise entrelaçado com a regressão da subjetividade contemporânea: o que a desmedida do amor passional e o funcionamento-limite têm a dizer? Revista Brasileira de Psicanálise, 54 (2), 319-343.

Baptista, M. N., Baptista, A. S. D., \& Oliveira, M. G. (1999). Depressão e gênero: por que as mulheres deprimem mais que os homens? Temas em Psicologia, 7(2), 143-156.

Beck, A. T., Steer, R. A., \& Garbin, M. G. (1988). Psychometric properties of the beck depression inventory: Twenty-five years of evaluation. Clinical Psychology Review, 8, 77-100.

Beck, A. T., \& Steer, R. A. (1993). Beck Depression Inventory. Manual. San Antonio: Psychology Corporation.

Beck, A. T., Ward, C. H., Mendelson, M., Mock, J., \& Erbaugh, G. (1996). An inventory for measuring depression. Archives of General Psychiatry, 4, 53-63.

Berlinck, L. (2008). Melancolia e contemporaneidade. Recuperado em 10 de maio, 2010, de <http://www.fflch.usp.br/df/espinosanos/ARTIGOS/numero\%2018/luciana18>.

Brum, E. H. M. (2004). Patologias do vazio: um desafio à prática clínica contemporânea. Psicologia, Ciência e Profissão, 24, 48-53.

Corry, N., Merritt, R. D., Mrug, S., \& Pamp, B. (2008). The factor structure of the narcissistic personality inventory. Journal of Personality Assessment, 90(6), 593-600. 
Cunha, J. A. (2001). Manual da versão em português das escalas Beck. São Paulo: Casa do Psicólogo.

Cramer, P., \& Jones, C. J. (2008). Narcissism, identification, and longitudinal change in psychological health: dynamic predictions. Journal of Research in Personality, 42, 1148-1159.

Faveret, B. M. S., Mendonça, A. L. S, Coelho, E. R, \& Faustini, R. R. (2007). Eros no século XXI: Édipo ou Narciso? Tempo Psicanalítico, 39, 35-50.

Ferrari, M. A. L. D. (2006). O papel da diferença na construção da identidade. Boletim de Psicologia, 55(124), 1-8.

Giddens, A. (2002). Modernidade e identidade. Rio de Janeiro: Zahar.

Gorenstein, C., Pang, W. Y., Argimon, I. L., \& Werlang, B. S. G. (2011). Inventário Beck de Depressão-II. Manual. São Paulo: Casa do Psicólogo.

Hall, S. (2002). A identidade cultural na pós-modernidade. Rio de Janeiro: DP\&A.

Hill, W. R., \& Yousey, P. G. (1998). Adaptive and maladaptive narcissism among university faculty, clergy, politicians, and librarians. Current Psychology, 17, 163-169.

Hutz, C. S. (2000). Adaptação brasileira da escala de autoestima de Rosenberg. Curso de Pós-Graduaçáo em Psicologia do Desenvolvimento, Universidade Federal do Rio Grande do Sul, Porto Alegre, RS. Mimeo.

Hutz, S. C., \& Zanon, C. (2011). Revisão da adaptação, validação e normatização da Escala de Autoestima de Rosenberg. Avaliação Psicológica, 10(1), 41-49.

Kelly, G. (2006). Rising rates of depression in today's society: Consideration of the roles of effort-based rewards and enhanced resilience in day-to-day functioning. Neuroscience \& Biobehavioral Reviews, 30, 497-510.

Kubarych, T. S., Deary, I. J., \& Austin, E. J. (2004). The narcissistic personality inventory: factor structure in a non-clinical sample. Personality and Individual Differences, 36, 857-872.

Lasch, C. (1983). A cultura do narcisismo. Rio de Janeiro: Imago.

Lipovetsky, G. (1989). A era do vazio. Relógio de Água, 3, 47-74.

Magalhães, M., \& Koller, S. H. (1994). Relação entre narcisismo, sexo e gênero. Arquivos Brasileiros de Psicologia, 46(3/4), 77-93.

Martin, D., Quirino, J., \& Mari, J. (2007). Depression among women living in the outskirts of São Paulo, Southeastern Brasil. Revista de Saúde Pública, 41(4), 591-597.

Miller, A. (1981). Prisoners of childhood. New York: Basic Books.

Monti, M. R. (2008). Contrato narcisista e clínica do vazio. Revista Latinoamericana de Psicopatologia Fundamental, 11(2), 239-253.

Pincus, A. L., Ansell, E. B., Pimentel, C. A., Cain, N. M, Wright, A. G. C., \& Levy, K. N. (2009). Initial construction and validation of the pathological narcissism inventory. Psychological Assessment, 21, 365-379. 
Raskin, R., \& Terry, H. (1988). A principal-components analysis of the Narcissistic Personality Inventory and further evidence of its construct validity. Journal of Personality and Social Psychology, 54(5), 890-902.

Rosenberg, M. (1989). Society and the adolescent self-image. Revised edition. Middletown, CT: Wesleyan University Press.

Savietto, B. B., \& Cardoso, M. R. (2006). Adolescência: ato e atualidade. Revista Mal-Estar e Subjetividade, 6(1), 15-43.

Savietto, B., \& Cardoso, M. (2012). Idealização e onipotência na juventude contemporânea: a drogadicção como ilustração. Fractal: Revista de Psicologia, 24(2), 353-366. Recuperado em 13 de março, de 2011 <http://www.uff.br/periodicoshumanas/index.php/Fractal/article/ view/476>.

Sennett, R. (1975). Vida urbana e identidad personal: los usos del desorden. Barcelona: Península. Tajfel, H. (1984). Grupos humanos y categorías sociales: estudios de psicología social. Barcelona: Herder.

Teng, C. T., Humes, E. C., \& Demetrio, F. N. (2005). Depressão e comorbidades clínicas. Revista de Psiquiatria Clínica, 32(3), 149-159.

Trzesniewski, K. H., Donnellan, M. B., \& Robins, R. W. (2008). Do today's young people really think they are so extraordinary? An examination of secular trends in narcissism and self-enhancement. Psychological Science, 19, 181-188.

Trzesniewski, K. H., \& Donnellan, M. B. (2010). Rethinking "Generation Me": A study of cohort effects from 1976-2006. Perspectives in Psychological Science, 5, 58-75.

Twenge, J. M., Konrath, S., Foster, J. D. W., Campbell, K., \& Bushman, B. J. (2008). Egos inflating over time: A cross-temporal meta-analysis of the narcissistic personality inventory. Journal of Personality, 76, 875-901.

Twenge, J. M., \& Foster, J. D. (2010). Birth cohort increases in narcissistic personality traits among American college students, 1982-2009. Social Psychological and Personality Science, $1,99-106$.

Twenge, J. M. (2013). The evidence for generation me and against generation we. Emerging Adulthood, 1, 11-16.

Westen, D. (1990). The relations among narcissism, egocentrism, self-concept, and self-esteem: experimental, clinical and theoretical considerations. Psychoanalysis and Contemporary Thought, 13, 183-239.

Recebido em 13 de fevereiro de 2013 Aceito para publicação em 01 de junho de 2014 